\title{
Critical theory and Positive Organizational Scholarship
}

By: Arran Caza and Brigid Carroll

Caza, A. \& Carroll, B. (2012). Critical theory and Positive Organizational Scholarship. In K.S. Cameron \& G.M. Spreitzer (Eds.) Handbook of Positive Organizational Scholarship (pp. 965978). New York, NY: Oxford University Press. http://dx.doi.org/10.1093/oxfordhb/9780199734610.001.0001

Pages 965-978, Handbook of Positive Organizational Scholarship edited by Gretchen M. Spreitzer and Kim S. Cameron, 2012, reproduced by permission of Oxford University Press, https:/global.oup.com/academic/product/the-oxford-handbook-of-positiveorganizational-scholarship-9780199734610

***:C 2012 Oxford University Press. Reprinted with permission. No further reproduction is authorized without written permission from Oxford University Press. This version of the document is not the version of record. $* * *$

\begin{abstract}
:
This chapter uses a critical theory perspective to consider previous work in positive organizational scholarship (POS). Questions raised by the critical management studies (CMS) concepts of performativity, denaturalization, and reflexivity highlight areas in which POS could benefit from a more critical approach. Specifically, this chapter calls on POS to be more explicit about its intended aims, to be careful of universalizing notions of positivity, and to consider the implications of some its seemingly innocent choices. Specific examples of how POS has done well and poorly in these areas are offered, as a first step toward an informative dialogue between POS and CMS. Such a dialogue is important, both for the likelihood of POS achieving its stated aim of creating beneficial change and for the continuing relevance of POS in the larger field of organizational studies.
\end{abstract}

Keywords: Critical management studies | performativity | reflexivity | denaturalization

\section{Book Chapter:}

To introduce this chapter, we invite the reader to imagine that they are preparing a presentation about their latest research. You will be speaking to a cross-section of military personnel. It will be a large group of late-career, senior officers, and almost entirely men. Imagine that you prepare your presentation for this audience, but then arrive to find that, instead, you will be speaking to a small group, almost entirely women, all of whom are new officers who have been identified as future leaders. Would you have prepared differently if you had known? Would you be thinking about how to adjust your talk even as you approached the podium? We suspect so. As a result of mistaken assumptions, your efforts to create a useful talk may go awry. At a minimum, your talk will not be as effective as it might have been, and it could be a failure. 
In this example, we would have liked to correct your misunderstanding before you finalized the talk, to give you the chance to help your audience as much as possible. This chapter has the same intent. Our reading suggests that some prevalent assumptions may be stopping positive organizational scholarship (POS) from achieving what its participants intend, and our aim is to highlight those assumptions. Specifically, we challenge the POS community to consider the possibility of managers and nonmanagers working together in new, strikingly different ways to create futures that are more dynamic and ambiguous than those envisioned by mainstream organizational studies, but which are also more empowering and more humane. We hope that this chapter will help to prevent the enthusiasm and good intentions of POS from going astray. As stated repeatedly in descriptions of POS, the goal is to improve the lives of those in organizations, to encourage flourishing and thriving. This is a laudable goal, and one we would like to support.

However, as we tried to suggest with the opening example, good intentions and good research do not guarantee good outcomes. Assumptions determine what actions are taken, and the consequences they produce. Highlighting this powerful influence from assumptions is an important part of critical (p. 966) management studies (CMS), and is at the heart of our chapter. We adopt a critical perspective here, because we worry that without it, POS may not be as effective as it could be in contributing to beneficial change. We hope to provoke insights and new thinking by using a critical perspective to highlight aspects of POS that may not have been explicitly examined before, but which nonetheless have significant consequences. By examining some of the assumptions and language used in POS, we intend to highlight potential contradictions and to create space for different interpretations and perspectives.

In some ways, this chapter is an example of how a POS-CMS dialogue might begin, because it is a product of addressing contradictions. One of the authors self-describes as a critical management researcher similar to Alvesson (2008, p. 17) in having "a moderate version of constructionism, some interest in 'reality out there,' some in ideologies/discourses and subjectivity, plus some interest in the specifics and details of language ... radical humanism with a clear postmodernist (poststructuralist) bent." In contrast, the other author has pronounced positivist and modernist leanings, and despite being sensitive to the critiques of those positions, agrees with Parker (1995) in believing in the utility of "truth" as a concept. Writing together led to negotiation between our differing views about knowledge, the role of the researcher, and the aim of the argument. These differences are not resolved, nor should they be. The goal here is dialogue, not conclusion. We hope to provoke similar dialogue and rethinking between CMS and POS.

In keeping with this goal, we have made an effort to engage POS in its own terms when possible. Our reading of POS suggests that it is based in a modernist, science-oriented ontology. The majority of POS research that we examined makes assumptions about the "true" nature of people and aims to use the scientific method to uncover enduring, universal knowledge in the service of progress. This contrasts with most of CMS, in which the prevalent position is constructionism, in which any "truth" is a product of complex relational, situational, and contextual dimensions (Alvesson, 2008). In this view, knowledge can never be treated as "facts," in the sense of being value neutral; any claim of truth is an exercise of power that favors some at the expense of others. Because of this ontological difference between POS and CMS, our comments sometimes 
take two forms. The first tries to express our concerns within the ontology adopted by POS. The second adopts a more consciously CMS paradigm, one that is often essential for the critique to be meaningful. We hope that this two-part format provokes new considerations for readers.

The chapter is organized in five sections. The first describes what we mean by CMS, and the second explains how we understand POS. These are followed by two sections in which we bring these understandings into contact. We first consider issues in how the aims of POS are formally stated, and then we do the same with some examples of how POS research has been reported. We conclude with possibilities for continuing the dialogue.

\section{Critical Theory in Management Studies}

We begin by describing the specific critical perspective that we use in this chapter. This is important, because there is no normative agreement on the aims and content of critical theory. In the most traditional and historical sense, critical theory refers to the work of the Frankfurt school and associated scholars such as Adorno, Marcuse, Habermas, and Anderson. However, in practice, "critical theory," and the even narrower "critical management studies," involves a range of perspectives, which have been characterized as different branches (Alvesson, 2008) or competing arguments (D. Grant, Iedema, \& Oswick, 2010). As a general approach, CMS is probably most widely known for its critique of management and life inside organizations, and is often characterized as displaying a negative attitude toward organizations. In fact, it is the "experience of unhappiness which is the wedge critical theory uses to justify" its observations and critique (Alvesson \& Willmot, 1992, p. 439). Implicit in this is an oppositional stance toward management, which suggests that "to be engaged in critical management studies means, at the most basic level, to say there is something wrong with management as a practice and as a body of knowledge" (Fournier \& Grey, 2000, p. 16). This view argues that organizations should not be "presented as a self-evident force for good" (Alvesson, Bridgeman, \& Willmot, 2010, p. 6) and that there is always a dark side in management practice (Alvesson, 2008).

Described this way, CMS would seem to be the opposite of POS. Where POS seeks to highlight the positive aspects of organizational life, CMS is often seen as most concerned with the negative. However, we do not agree. For one, as we discuss below, "positive" and "negative" are descriptors that require significant qualification. They are only meaningful if one answers fundamental questions such as "positive for whom?" and "to what effect?" Moreover, although (p. 967) CMS may be most visible in its antimanagement position, the intent of critical theory is not inherently antimanagement (Alvesson \& Willmot, 1992). In our view, being critical means paying attention to that which is absent, marginalized, or silenced in the business of organizing (Alvesson, 2008). Critical management studies recognize that people are shaped by the interdependence of organizing, and that this shaping inevitably favors some parties at the expense of others. It is therefore important to recognize these asymmetries in an effort to make organizations "less irrational and socially divisive" (Fournier \& Grey, 2000, p. 23). In particular, Horkheimer (1976, p. 220) described critical theory as being "motivated by the effort to transcend the tension and to abolish the opposition between the individual's purposefulness, spontaneity, and rationality, and those work-process relationships on which society is built." 
Our approach in this chapter builds on Fournier and Grey's (2000) three elements of performativity, denaturalization, and reflexivity, supplemented by Spicer, Alvesson, and Karreman's (2009) critique of the performativity component. Fournier and Grey (2000) offered their three elements as a minimal set that could be used to characterize CMS as a whole. Their formulation has attracted many supporters, but also many detractors. For example, Thompson (2004) noted that some work that is not part of CMS involves aspects of the three elements, and that some work that all would agree is part of CMS does not consider the three elements particularly significant. Even allowing these concerns, we believe that Fournier and Grey's (2000) three elements offer a promising place to begin our pursuit of a CMS-POS dialogue. Therefore, we discuss each of the three elements below, then use them as a framework to highlight how a critical perspective might influence the development of POS.

Following Fournier and Grey (2000), we use performativity to refer to the issue of automatically making traditional business-related outcomes (e.g., efficiency, profit) the top priority in organizations. Adopting a critical perspective helps to highlight the default and unquestioned dominance of economic performance in mainstream organizational studies; financial results are typically treated as the most important of all outcomes. Admittedly, profit may be a valid and important goal in many situations, but its validity and importance should be assessed, not treated as automatic or exclusive of other concerns. The logic of maximizing output from minimum input is only one way to assess organizational life, and its preeminence should be challenged. There may be many other outcomes of equal or greater value (e.g., health, peace, development).

However, as Spicer and colleagues (2009) note, simply challenging the dominance of economic performance is not sufficient. A purely antiperformance stance commits to negativism by failing to offer a solution for change. As such, an alternative performance standard must be provided. Spicer and colleagues (2009) propose a critical performativity comprised of five elements: affirmative stance, normative orientation, working with potential, pragmatism, and ethic of care. Their argument is that judgments of organizational success must include these criteria, not simply financial results. Outcomes other than business performance can be valuable in themselves, not just as means to economic ends. Autonomy, democracy, equality, ecological balance, and other outcomes may be desirable for their own sake, independent of, and potentially even in conflict with, organizations' economic performance (Alvesson, 2008).

Denaturalization concerns revealing the constructedness of organizations and organizing processes. That is, it makes visible the "un-naturalness' or irrationality" of current practice (Fournier \& Grey, 2000, p. 18). In the absence of denaturalization, existing social processes can be reified or experienced as "natural," and this assumption of naturalness prevents the consideration of alternatives (Weick, 2006). Activities and relationships established for the sake of organizing become legitimized and inviolable when they are viewed as inevitable, objective states. For example, if all business organizations are arranged in part around power-based hierarchies, one may come to believe that hierarchy is inherently part of organizing, rather than merely an aspect of how organizing is currently practiced. Denaturalization calls for examination of the historical, cultural, and social construction of current practices, so that they cannot be assumed to be inevitable or inherent. 
Reflexivity calls for an awareness of one's personal practice and its implications. This applies both to philosophical and methodological concerns. In the absence of reflexivity, one imposes one's own assumptions on what is treated as relevant, and even possible (Fournier \& Grey, 2000). Reflexivity asks that researchers consider the influence that arises from what they pay attention to and what they create through their actions. For example, reflexivity highlights that "objectivity, neutrality, and universality" are working ideologies, rather than existential (p. 968) realities (Alvesson, Bridgeman, \& Willmott, 2010, p. 9). As such, positivism is an approach to be argued for, not an assumption from which to begin. Epistemologies and ideologies are always part of research, but they should be handled with an awareness of their presence and their consequences.

These three elements are closely interrelated, and serve not so much as a template, but as a guide to inquiry. Each element suggests questions with which one may consider the work of a discipline such as POS (see Table 73.1). In this chapter, we begin to ask these questions of POS. In doing so, we hope to prevent POS from falling into the traps its predecessors have, so that it does not become a "false and stunted humanism ... wanting change without really changing anything" (Aktouf, 1992, p. 412).

\section{Our Interpretation of Positive Organizational Scholarship}

To say anything about POS requires first clarifying what constitutes POS. Doing so involves defining boundaries, which is of particular significance to those advocating a critical perspective. Critical management studies are concerned with the marginalized and the excluded, with the exercise of power inherent in allocating status. Assigning membership is necessarily an act of exclusion: Some will be given status and recognition while others are excluded.

Since POS is still comparatively new, and is intended to be encompassing of diverse work (Cameron, Dutton, \& Robert E. Quinn, 2003b), the specifics of what is and is not POS are ambiguous. In recognition of this, we adopted a conservative approach, with the intent of choosing an interpretation of POS that we believe would be recognized and accepted by most insiders. This influenced several of our decisions about what we would treat as constituting POS. For one, we chose to follow stated POS practice and restrict our consideration to studies of organizational phenomena (Cameron et al., 2003a; Dutton \& Sonenshein, 2009). Positive organizational scholarship has been described as the contextualized cousin of positive psychology, as it pursues the same humanistic aims, but does so with particular attention paid to the role of organizational processes and environments (Dutton \& Glynn, 2008; Dutton, Glynn, \& Spreitzer, 2006). In keeping with this, we limited ourselves to organizational studies. As well, consistent with prior POS claims (Dutton et al., 2006; Roberts, 2006), we considered research identifying itself as part of the positive organizational behavior (POB) tradition to be part of the larger POS whole.

The second decision we made was to restrict our consideration to peer-reviewed journal articles. In doing so, we do not intend to denigrate the importance of nonreviewed scholarship, but we believe that this decision is consistent with the stated aims of POS, which stress the importance of "empirical (p. 969) credibility and theoretical explanations [based on] rigorous, systematic, and theory-based foundations [that show] consistency with scientific procedures in drawing 
conclusions" (Cameron et al., 2003a, p. 6; also see Cameron, 2007; Dutton et al., 2006). The only exception we made to the reviewed article decision was the inclusion of eight book chapters that are formal statements of the nature of POS (discussed below).

Table 73.1. Three elements of critical inquiry

\begin{tabular}{|c|c|c|}
\hline Element & Description & Questions Raised \\
\hline $\begin{array}{l}\text { Critical } \\
\text { performativity }\end{array}$ & $\begin{array}{l}\text { Challenge the automatic dominance } \\
\text { of financial and economic } \\
\text { performance; consider other } \\
\text { outcomes that may be of equal or } \\
\text { greater importance in } \\
\text { organizations. }\end{array}$ & $\begin{array}{l}\text { What goals and values does POS explicitly pursue? } \\
\text { What goals and values are implicitly supported, because they } \\
\text { are not challenged? } \\
\text { What, if any, outcomes are just as important as profit? } \\
\text { What, if any, outcomes are worth pursuing, even at the } \\
\text { expense of profit? }\end{array}$ \\
\hline Denaturalization & $\begin{array}{l}\text { Recognize the constructed nature of } \\
\text { judgments and labels. }\end{array}$ & $\begin{array}{l}\text { What is being taken for granted about: } \\
\text { Individuals? } \\
\text { Groups? } \\
\text { Relations among people? } \\
\text { The nature of organizing? } \\
\text { What possibilities do these assumptions preclude? }\end{array}$ \\
\hline Reflexivity & $\begin{array}{l}\text { Consider the implications of one's } \\
\text { choices and the possibilities that } \\
\text { those choices preclude. }\end{array}$ & $\begin{array}{l}\text { Who and what are (implicitly) made negative by not } \\
\text { receiving the label "positive"? } \\
\text { What does POS make most important in organizations? } \\
\text { Who and what is studied? In what ways? } \\
\text { How do these choices influence what POS can say, and how } \\
\text { it can say it? }\end{array}$ \\
\hline
\end{tabular}

However, even restricting attention to peer-reviewed articles addressing organizational phenomena still leaves considerable uncertainty about what constitutes POS. For example, since POS has repeatedly been described as "not new," in the sense that it makes no claim to have invented a focus on positive phenomena, but rather aims to unite relevant previous work (Cameron, 2007; Cameron et al., 2003a; Dutton \& Glynn, 2008; Dutton \& Sonenshein, 2009), there are many scholars who could be understood to have been "doing" POS before POS existed. This raises the question of whether their recent work should be considered part of POS. As well, in addition to the work that explicitly draws on statements of POS, an even larger body of research appears to be studying phenomena claimed as part of POS. For example, using the Social Science Citation Index to conduct forward citation searches on the 11 formal statements of the domain of POS, as well as on Luthans' (2002) description of POB, we found more than 100 articles (based on a search conducted March 20, 2010). If one expands this to an ABIINFORM database search of the years 2002-2010 using POS keywords such as "thriving" and "flourishing," the potential literature of POS increases by more than 200 articles (again, as of March 20, 2010). We suspect that POS insiders would assign these more than 300 articles varying degrees of inclusion, and that some would be excluded.

Therefore, to be confident that what we are critiquing is only what "truly is" POS, we adopted a more restrictive list. Using the website of the Center for Positive Organizational Scholarship (http://www.bus.umich.edu/Positive) and the publication records of the three POS founders (i.e., Cameron, Dutton, and Quinn; see Bernstein, 2003), we were able to identify three articles and eight chapters that appear to be official statements about the nature of POS. We used these to form our interpretation of what POS is formally espoused to be. We then developed a list of 35 peer-reviewed articles that appear to be unequivocally POS research, as they are officially 
endorsed by the Center for POS. ${ }^{1}$ We used the Center's own list of recent publications (http://www.bus.umich.edu/Positive/CPOS/Publications/recentworkingpapers.html, accessed March 18, 2010), historical report (Center for Positive Organizational Scholarship, 2007), report of research impact (Center for Positive Organizational Scholarship, n.d.), and current activity highlight report (Center for Positive Organizational Scholarship, 2010) to identify the 35 articles that we used in our analysis of enacted POS.

\section{Positive Organizational Scholarship As Espoused}

In this section, we ask questions that are raised by a critical examination of the 11 formal statements of the domain of POS. These statements often summarize the nature of POS by contrasting it with what POS is not. For example, "theories of problem solving, reciprocity and justice, managing uncertainty, overcoming resistance, achieving profitability, and competing successfully against others" are used as examples of organizational phenomena that are of relatively little concern to POS (Cameron et al., 2003a, p. 3). Although not denying the importance of these issues, POS is positioned as a call to emphasize other phenomena, including "excellence, transcendence, positive deviance, extraordinary performance, and positive spirals of flourishing" (Cameron et al., 2003a, p. 3). Positive organizational scholarship describes itself as being concerned with every aspect of positive organizational phenomena, including their causes, consequences, and mechanisms (Dutton et al., 2006; Roberts, 2006; Spreitzer, 2008). It is argued that studying positive phenomena may provide new ways to understand familiar outcomes (e.g., authenticity's role in leadership, Avolio \& Gardner, 2005; the role of virtue in organizational performance, Cameron, Bright, \& Caza, 2004), and it may reveal important outcomes that have previously been neglected (e.g., compassion organizing, Dutton, Worline, Frost, \& Lilius, 2006; flow states, Ryan W. Quinn, 2005).

However, the specifics of positivity remain unclear (Caza \& Cameron, 2008; Fineman, 2006; George, 2004). The formal statements of POS have consistently stated that the discipline is concerned with understanding positive phenomena, but offered little guidance for distinguishing positive from negative. The most common device used to describe what constitutes positivity is reference to positive deviance: to "especially positive deviance from anticipated patterns ... that which is unexpectedly positive" (Cameron, 2007) or to "above (p. 970) normal, extraordinary states that are good, honorable, or virtuous" (Dutton et al., 2006, p. 642). However, these descriptions only defer the question, rather than answer it. One must then ask: Positively deviant relative to what? Who judges the honor or virtue of the result?

In this matter of emphasizing the positive, we are encouraged that POS explicitly recognizes its "positive bias" (Cameron, 2007, 2008b; Roberts, 2006), avowing a consciously normative perspective (Cameron et al., 2003a; Dutton \& Glynn, 2008). It is helpful that POS openly positions itself as committed to advancing a value-based agenda and to creating change in service of that agenda (Caza \& Cameron, 2008; Dutton \& Glynn, 2008): "The focus is on the

\footnotetext{
${ }^{1}$ The Center for POS sources actually suggested 36 articles, but we excluded the article by Spreitzer, Stephens, and Sweetman (2009), because its report on the effect of the Reflected Best Self Exercise (RBSE) did not seem to fit the "organizational" criterion of POS. Although the RBSE was developed by POS researchers, this particular study examined its effects on a group of high school students at a three-day conference, rather than in an organizational or work context.
} 
creation, diffusion, and legitimation of POS practices in business units and organizations" (Dutton et al., 2006, p. 642). This forthright admission of intent is an important change from more traditional work that hides behind the facade of value neutral science.

Nonetheless, more is required. It is not enough to admit bias and espouse a value-based agenda. The values in question must be made explicit, and their implications considered. Which specific values are being advanced? By implication, which other values are being denied? Why these values? Who chose? Who should choose? And what effect will advancing the preferred values have, particularly on those who may not share them? The benefit of admitting bias can only be realized if these sorts of questions are addressed, so that the likely effects of the bias may be examined. The POS failure to clarify the meaning of "positive" is subject to critique in at least two ways, each reflecting our (the authors') differing perspectives.

If one allows the positivist, modernist assumptions of POS, it might be argued that comprehensive definitions of complex empirical phenomena are difficult to achieve. Biology, for example, does not have a final definition of "life" (McKay, 2004), and in fact some scientists claim that trying to define life is not useful. They argue that definitions involve semantics, while the proper concern of biology is understanding organisms (Cleland \& Chyba, 2002). In keeping with this orientation, biology does not have a comprehensive definition of what life is, but it does have specific criteria for recognizing whether something is alive (e.g., homeostasis, metabolism, etc.). In this perspective, if POS cannot provide a final definition of what is positive, it should at least offer concrete criteria for its recognition. Examples of this include biology's characteristics of life and psychology's criteria for healthy mental functioning (American Psychiatric Association, 1994).

In contrast, a postmodern view would argue that positivity, like all phenomena, is open to multiple, partial, and often contradictory definitions, so that any attempt to delineate or define it is an act of power. This view would argue that a definition must be advanced, and that in doing so, POS must engage with the issues that arise from the act of defining. In particular, POS should consider how any definition of positivity includes some phenomena while excluding others. All uses of the label positive are consequential choices, not natural or neutral observations of fact. Defining positivity and recognizing that definition's constructedness would allow for contestation. It would reveal which parties and perspectives are legitimized (or not) by the stated nature of positivity. It would also create the possibility of alternative definitions, potentially allowing otherwise marginalized voices to be heard.

We believe that both critiques reveal the need for POS to clearly state its goals and desired outcomes, in the way that Spicer and colleagues (2009) advocated their five-part framework. Positive organizational scholarship should specify what it is trying to achieve in the name of positivity. For example, an important part of many CMS views is the emancipatory project, which is an aim to move individuals and groups toward greater freedom and autonomy (Alvesson \& Willmott, 1992). Critical management studies scholars who explicitly seek this aim must consider the meaning of emancipation, and how their actions and language facilitate its progress. Positive organizational scholarship would benefit from doing likewise concerning its own aims. Being clear about what is intended and whether a given action supports those aims will be crucial for POS to achieve its goal of improving organizational life. 
Moreover, we would argue that the need for clarity is especially important for POS because it involves the study of organizations, in which the traditional, economic performance standards have de facto dominance. If POS is not explicit about what constitutes positivity, then POS risks defaulting to the status quo of serving business outcomes. For example, one could read the claim that "by focusing on the generative dynamics of human organizing, POS provides an expanded view of how organizations can create sustained competitive advantage" (Cameron et al., 2003a, p. 10), as an effort to use positivity solely for profit. Even when a stronger position is taken, advocating for the inherent value of positive outcomes in themselves, an (p. 971) apologetic tone is often taken, with the promise that these positive outcomes will not interfere with the pursuit of profit. For example, "POS represents a perspective that includes instrumental concerns but puts an increased emphasis on ideas of 'goodness" (Cameron, 2007) and "... not only as a means to the desired end of strong economic performance, but also as ends worthy of explanation on their own" (Dutton et al., 2006, p. 642). In contrast to this tepid position, we agree with those who have observed that the greatest potential from POS may be in the establishment of new "dependent variables," in defining new criteria that replace profit as the best standard of organizational success (Caza \& Cameron, 2008; Dutton \& Glynn, 2008). But if POS is going to do this and be the force for change that it aspires to be, it needs to be explicit about the nature of positivity.

Similarly, our reading suggests that POS would benefit from engaging in denaturalization. At present, most formal statements of POS assert universal agreement on, and desire for, positive states (Cameron, 2008b; e.g., Cameron \& Caza, 2004; Dutton et al., 2006). Positive organizational scholarship "advocates the position that the desire to improve the human condition is universal and that the capacity to do so is latent in most systems" (Cameron et al., 2003a, p. 10). The use of terms such as "instinct," "latent potential," and "universal" make the authors' views of what is positive automatic, even teleological. This is problematic for its implicit denigration of any state that the author does not endorse. Except for some brief and undeveloped mention of potential cultural differences (Caza \& Cameron, 2008; Dutton \& Glynn, 2008), the assumption of some universally positive state dominates POS. We commend POS authors for openly asserting their desire to move toward what they consider to be positive outcomes, but urge that those same authors be careful not to implicitly position their own desired states as a "natural" part of being human.

As an extension of this claim of universal positives, statements of POS also have a disturbing tendency to treat positivity as an unequivocal characteristic. In this view, anything either is or is not positive, in its entirety. References are made to positive states, positive processes, and positive outcomes, with relatively little discussion of the possibility that the same state might have both positive and negative aspects, or be perceived simultaneously as positive and negative by different parties (but see Dutton \& Sonenshein, 2009). In response, we would ask whether Wal-Mart, one of the world's largest and most influential organizations, is positive or negative. Evidence suggests that Wal-Mart creates economic success at the expense of locally owned, small firms offering similar goods and services (Irwin \& Clark, 2006). Moreover, although WalMart clearly contributes to a reduced cost of living (Basker, 2005a), it also seems to increase local poverty (Goetz \& Swaminathan, 2006). The presence of a Wal-Mart raises local employment levels, but does so by shifting jobs away from some sectors toward others 
(Basker, 2005b), and Wal-Mart's presence may simultaneously contribute to reduced social capital (Goetz \& Rupasingha, 2006) and increased entrepreneurial success (Goetz \& Shrestha, 2009). Given all of this, it is hard to imagine that Wal-Mart is solely positive or negative, thus demonstrating the problems of assuming that anything can be entirely positive or not.

An important implication of this observation is the value of greater reflexivity when advocating POS. Although every statement of POS includes the caveat that the authors do not deny the importance of negative phenomena, there are nonetheless powerful implications in the use of positive-negative labeling. Even if the negative phenomena are not explicitly denigrated, they are cast in opposition to phenomena described as creating "goodness, generativity, growth" (Dutton \& Sonenshein, 2009), and which foster "excellence, thriving, flourishing, abundance, resilience, or virtuousness" (Cameron, 2007). Moreover, it is not only organizational phenomena, but, by implication, the people who participate in them and who research them, that are cast as being contrary to these evocative, powerful states. Even if POS authors do not intend harm, we urge consideration of the unintended consequences of the powerful language used by POS.

In addition, POS authors should consider the criteria that they are implicitly advancing when judging one state positive and another not. As we noted earlier, no explicit standard of positivity has been offered, but every use of the label "positive" nonetheless implies one. Since positivity involves "desirable deviance" relative to some standard, any act of labeling something positive implicates a specific set of desires and reference standards. To the extent that these desires and standards remain unstated, they are protected from scrutiny. This has the effect of implying their unquestionable rightness, which brings us back to the point that began this section: We laud the fact that POS is open about its advocacy, but suggest that unless the intent (p. 972) of that advocacy is to perpetuate the status quo, it is crucial to specify the change that is desired.

\section{Positive organizational scholarship As Enacted}

In this section, we consider several themes that we see running through the 35 peer-reviewed articles that are officially part of POS. These themes concern the nature of positivity, the problem of performance standards, the relative importance of managers versus employees, and a disturbing historical trend. In each case, we summarize the theme, and then raise questions suggested by the critical perspective we have adopted. We also offer examples of POS research that does not fit the theme, and which seems to be moving in a direction that we consider more promising.

\section{Problematic Positivity}

In addressing the issue of what is positive, POS articles tend to adopt one of three approaches (Cameron, 2008b). The first is to assert the natural or obvious character of positivity. In this approach, it is claimed that everyone has an instinctive drive toward the same ideals; that in our true hearts, we all know and agree on what is positive (e.g., Caza, Barker, \& Cameron, 2004). These claims are usually based in some historical tradition, such as ancient Greek philosophy (Cameron et al., 2004) or world religious practice (Kanov et al., 2004). In all cases, it is 
problematic for reasons we have already addressed. Giving one's belief about what is good the label "instinctive" or "natural" makes other beliefs wrong and unnatural, even inhuman.

The second approach is related, in that it also presumes the obviousness of positivity, but does so by not addressing the matter at all (e.g., Carmeli \& Spreitzer, 2009; Dutton et al., 2006; Ryan W. Quinn, 2005). These articles may mention POS or the importance of studying positive phenomena, but little effort is made to define what constitutes positivity. These articles typically argue for the important consequences associated with their focal construct, but offer no explanation for why those consequences are positive or to be preferred over any others. This approach takes the risk of having the positive label seem arbitrary. As a concrete example, we found six of the 35 articles particularly mysterious (Berg, Wrzesniewski, \& Dutton, 2010; James \& Wooten, 2005; Lawrence, Lenk, \& Robert E. Quinn, 2009; Ryan W. Quinn \& Dutton, 2005; Wooten et al., 2005). These articles make no explicit mention of positivity, and it is not obvious to us why they have been designated as POS research while any number of other articles has not.

In contrast to these two, the third approach tries to define positivity explicitly by focusing on its exceptional nature. In this approach, POS concerns phenomena "exceeding normal happiness and excellence ... an affirmative exception to typical organizational behavior" (Cameron \& Caza, 2002, pp. 33-34). This "positive deviance" approach is concerned with "intentional behaviors that depart from the norms of a referent group in honorable ways" (Spreitzer \& Sonenshein, 2004, p. 834). In other words, if it is good and rare or unlikely, it is positive. Although this does not constitute a satisfactory definition, it has at least recognized the subjective nature of judgments about goodness. In particular, Spreitzer and Sonenshein (2004) proposed that POS be concerned with four reference groups for judging positive deviance: the unit or organization, the industry, professional practitioners, and what they refer to as "general principles." In each case, it is suggested that knowledgeable insiders should determine how honorable a given deviation is. These authors also recognize that two groups may judge the same act in different ways, but do not develop the matter.

From a critical perspective, it is useful to have defined the reference groups and to have proposed judges because doing so allows for discussion of whether these choices are desirable ones. We encourage POS researchers to have this discussion, to consider whether these four groups are the best referents and whether expert insiders are the preferred judges. They may not be. For example, if POS is concerned with creating change, then using insider judges may be counterproductive. A deviance that is beneficial to a group disempowered by the existing social structure may seem threatening and dishonorable to the insiders favored by current practice. As a result, the use of insider judges could restrict the status of "positive" to that which perpetuates the status quo. This will work against change, rather than for it. A better approach would be to recognize the contentious nature of defining positive, and to examine the implications of competing interpretations. A POS example of this appears to be developing in discussions of identity. Dutton and colleagues have recognized that it is problematic to simply label an identity as positive or not; they consider four different bases for assigning such a label, and the differing implications of each (Dutton, Roberts, \& Bednar, 2010). We believe that this sort of reflexive, multiperspective approach is a more fruitful direction as POS grapples with the meaning of "positive." 


\section{Economic Performance}

Earlier, we noted that if POS did not clearly define its own positive performance criteria, then it was at risk of adopting the economic criteria that have priority in mainstream organizational studies. The large majority of POS articles published so far confirm this fear. Most of the 35 articles treat organizations' economic performance or related business goals as the ultimate end of positive states and practices.

In many cases, the use of POS to serve economic ends was framed as incidental. That is, the positive phenomenon was described as inherently valuable, but also having the happy side effect of enhancing profits. For example, one article on the virtue of organizational forgiveness noted that instrumental motives are antithetical to virtue, that "if forgiveness produced no personal or organizational advantage, it would still be desirable because of its intrinsic goodness. Nonetheless, ... there is some reason to believe that virtues in general, and forgiveness in particular, may lead to personal and social benefits" (Cameron \& Caza, 2002, p. 40). Similarly, although compassion was argued to be important because it was a natural human response to the suffering of others, it was also noted that such compassion "may be particularly important for sustained organizational survival and effectiveness.... Pain and suffering have serious implications for organizational performance and productivity," (Kanov et al., 2004, pp. 810811), because "compassion shown by work colleagues can strengthen emotional connections at work and boost people's ability to function as productive employees" (Lilius et al., 2008, p. 194). Other POS articles made similar observations about phenomena such as humanistic organizational practices (Wooten \& Crane, 2004), employee self-actualization (Wooten \& Crane, 2002), and energizing communication (Ryan W. Quinn \& Dutton, 2005).

In other cases, the preeminence of economic gain was more explicit: POS was required to serve monetary aims. One article observed that "an irony associated with organizational virtuousness is that without demonstrated benefits, virtuousness is unlikely to capture much interest in organizational research ... without pragmatic outcomes" (Cameron et al., 2004, p. 770). In another, organizational resilience was promoted as a promising management strategy for preserving shareholder profit (Gittell, Cameron, Lim, \& Rivas, 2006). Some articles went even further, with alarming undertones that seem to offer POS constructs as a way to further management control of employees. For example, one article described how most people have altruistic inclinations, and how organizations can use these inclinations as a tool for increasing employees' organizational commitment (A. M. Grant, Dutton, \& Rosso, 2008). Another article observed that the knowledge-based nature of modern work is undermining managers' ability to monitor and evaluate subordinate employees and proposed the use of POS constructs as new performance metrics for managers' control (Ryan W. Quinn, 2005). In the most disturbing case, promoting employee thriving was explicitly suggested as a less expensive way to get more from employees:

Today's work environment requires more ingenuity and fresh ideas from employees.... Organizations can no longer survive by doing more of the same. Although we often hear about the impressive benefits and perks that companies like Google or SAS offer their employees to motivate creative and innovative behaviors, this research suggests that there may be cheaper and more sustainable ways to enable employee innovative behaviors. 
Generative relationships that enable human thriving at work (i.e., learning and vitality) are less expensive alternatives than high priced gourmet meals, workplace concierges, or in-house masseuses (Carmeli \& Spreitzer, 2009, p. 196).

Admittedly, only this last article was so explicit as to say that POS offers a way for management to squeeze more from employees, but most were implicitly compatible with this view. In advancing the observation that positivity is also good for the bottom line, POS does nothing to challenge the dominance of financial measures as the ultimate performance standards. As a result, the priorities of mainstream organizational studies may co-opt the humanistic mission of POS.

However, there were also exceptions, articles that challenged the dominance of profit by at least proposing other outcomes that were equally important (e.g., Wooten et al., 2005). For example, in defining the construct of thriving, the authors focused on it as a source of health, individual achievement, and growth in all aspects of life (Spreitzer, Sutcliffe, Dutton, Sonenshein, \& A. M. Grant, 2005). It was noted that thriving could also contribute to work performance, but this was clearly secondary; it was presented as an incidental consequence of the fact that the thriving individual had a job. Similarly, the POS call for more participatory leadership and empowerment in organizations was not grounded in any potential benefit for business, but rather in (p. 974) the ability to contribute to world peace (Spreitzer, 2007). Going further still, one article presented a case study in which organizational resources and routines were subverted to care for members whose lives outside the organization were in turmoil (Dutton et al., 2006). This article celebrated the act of compassion for its own sake, making no effort to justify compassion in terms of economic or financial gain.

It is our belief that POS will make its most important and transformative contributions only if these exceptions become the rule. In this, we will restate our claim from the previous section. Positive organizational scholarship must be conscious and explicit about the nature of the positive change it wishes to promote. Stating a goal of greater physical health, increased world peace, more compassionate organizations, or something else of this sort will provide direction and the possibility of resisting the dominant economic metrics. Without such a goal, as suggested by the majority of POS research already published, financial concerns will take control.

\section{Privileging Management}

If a dominant narrative runs through the POS articles, it is of formal organizational leaders who are well-intentioned and innocent victims that prevail despite challenging environments. Bad things happen to these good people, but their essential heroism allows them to take actions that engender positive states in their employees and produce unexpected organizational performance. Consistent with this narrative, most of the positivity in POS articles is described as originating in authority figures. Thus, the articles emphasized how leaders and managers provide role models for employees (Cameron \& Caza, 2002; Heaphy \& Dutton, 2008), create policies that lead employees to do good deeds (A. M. Grant et al., 2008; Wooten \& Crane, 2002), and generally shepherd employees from crisis to success (James \& Wooten, 2005; Spreitzer, 2006; Wooten \& James, 2008). The prevalent assumption that employees need their positive inclinations to be legitimized or institutionalized by leaders (e.g., Bright, Cameron, \& Caza, 2006; 
Cameron, 2008a; Kanov et al., 2004), means that educators must teach tomorrow's managers how to put virtue into their organizations (Cameron, 2006). In this view, except for participating in the processes created by leaders, there is relatively little role for employees in contributing to positive states or outcomes.

This view is problematic for at least two reasons. The first is that it is untenable given what others have learned about leading. One hundred years ago, the study of leadership focused on "great men" who made things happen by exerting their will on effectively inert followers, but leadership scholars have since come to a consensus that this not a useful way to understand leaders (Avolio, Walumbwa, \& Weber, 2009). Leading is a negotiated outcome, in which the leader's social environment plays a fundamental role (Brass, 2001; Hunt \& Dodge, 2001; Salancik, Calder, Rowland, Leblebici, \& Conway, 1975). Followers are the most important and influential force in that social environment. They are contributors in leadership; leadership does not happen to them (Cogliser \& Schriesheim, 2000; Dirks \& Ferrin, 2002; Uhl-Bien, 2006). As such, we have trouble believing that there is no role for employees in fostering organizational positivity.

Moreover, the view that positivity arises primarily from formal leaders is fundamentally disempowering for employees. If employees have no role, except perhaps as transmitters in a process created by management, they are little more than automatons. Adopting and promoting such a narrative implies that employees cannot contribute to positivity, and therefore should not try; they should simply accept what is given or done to them by management. This view is incompatible with the emancipatory aims of CMS, and does not seem especially appropriate for the POS goal of fostering flourishing and generative states.

However, within the POS articles, there were exceptions to this leader-centric narrative. These articles challenged the assumption that managers were the key players in positivity. Some made individuals the most important determinants of their own outcomes (e.g., Roberts et al., 2005; Spreitzer et al., 2005). Others adopted more interactive views, with employees and management jointly creating positivity (e.g., Dutton et al., 2006; Spreitzer, 2007). Some went even further, and began to challenge mainstream assumptions about management control, questioning whether traditional bureaucratic structures were conducive to positivity (Wooten \& Crane, 2004) or calling for participation from those outside the organization, including communities, families, and individuals (Wooten et al., 2005). As before, we believe that these exceptions offer a better direction for POS. It is not clear to us how promoting management dominance and employee passivity will contribute to the stated aims of POS.

\section{Declining Relevance}

Spreitzer (2008) made the provocative admission that she wants POS to be a temporary phenomenon. She stated her hope that POS would reach its aims of creating positive change, and in doing so, make itself obsolete. In this hope, POS would no longer matter as a research perspective, because positive phenomena would be institutionalized and accepted to the extent that researchers and practitioners alike would give them the attention they deserve. Positive organizational scholarship would no longer need to champion positivity. Our reading of the POS 
articles leaves us suspecting that Spreitzer may have been correct about the coming obsolescence of POS, but we see a more dire cause: POS may be losing its impetus for change.

In the previous parts of this section, we have discussed our worries about POS being subordinated to economic goals and its potential role in disempowering employees. We have also noted that there are promising exceptions to these patterns. However, a striking feature of these exception articles is that they were all published between 2004 and 2007. None of the earliest or latest POS articles give much evidence of challenging the dominance of managers and economic performance. We find this troubling.

We suspect that the early articles may have been based on a strategic decision to avoid challenging traditional assumptions. Since POS was apparently intended to create change from within mainstream organizational studies (Bernstein, 2003), it may have been judged necessary to launch POS in terms that were familiar to the mainstream. Once those first, tame articles had established POS (i.e., 2002-2004), the subsequent articles could then begin to push against the boundaries, to challenge assumptions. Early POS work may have been intended as a bridge from the mainstream.

However, this logic does not explain why POS articles published in the last 3 years seem to have stopped challenging mainstream assumptions. If anything, we might have expected and hoped that the most recent work would have extended the trend, that it would be even more radical. Instead, the most recent articles either explicitly serve economic and management dominance, or do so complicitly by failing to offer any challenge and by carefully couching the value of positivity in terms consistent with mainstream priorities. This suggests that our fears about POS being co-opted by mainstream priorities are well-founded. If this apparent trend in POS research continues, then POS may indeed become obsolete, but not for the optimistic reasons that Spreitzer (2008) hoped. Rather, it will be because POS has nothing new to say.

\section{Conclusion}

It may seem ironic to bring a critical view to a movement explicitly founded to overcome negative scholarship (Cameron, Dutton, \& Robert E. Quinn, 2003a), but we believe there is a surprising potential for synergy between POS and CMS. At present, POS is in danger of failing to achieve its goal of creating beneficial change, because unquestioned assumptions are subverting positivity to financial gain and management dominance. However, as highlighted in this chapter, there are exceptions that show how POS has the potential to avoid this failure and do remarkable things. In service of that, we have tried to show how the questions raised by a critical perspective could benefit POS. If POS can offer an alternative performance criterion, one that is reflexively conscious of its implications, we believe it could contribute greatly to thriving in organizations.

However, doing so will require different ways of working. For example, returning to the military talk that opened the chapter, the traditional response to (p. 976) the mistaken assumption about the audience might be to give the talk as planned or to revise as you go. But what if you worked with your audience instead? You have your expertise, but they also have theirs. Perhaps you admit to them your assumptions and how they influenced you. In addition to discussing your 
findings, you might discuss what other findings could be useful, and the assumptions you made, with their implications for yourself and also for the military. This would create a very different conversation. To spark such conversations within POS, we end with some questions for consideration (see Table 73.2). Combined with the issues discussed here, we hope that these questions can help to direct POS toward reaching its laudable aims.

Table 73.2. Future directions

What constitutes "positive"? What specific aims is POS trying to achieve? What is the agenda?
If positivity lies in honorable deviance, who should judge the honor of the act? Which interests and groups are
favored by that choice of judges? Which ones are hurt?
Can anything be entirely positive (or negative)? If not, what implications does that have for the meaning of
positivity?
What is implicitly being labeled negative by not being included in positive? What effect will that have?
What new outcomes and dependent variables represent the greatest potential value of the POS perspective?
In defining positivity, which groups might have differing views? How many of those groups are included in the
conversation? How could the excluded parties be involved?

\section{Acknowledgments}

We appreciate the assistance of Jane Dutton, Gail Fairhurst, Eric Guthey, and Jim Walsh in helping us with the development of this chapter.

\section{References}

Alvesson, M. (2008). The future of critical management studies. In D. Barry, \& H. Hansen (Eds.), Sage handbook of new approaches in management and organization (pp. 13-26). Thousand Oaks, CA: Sage Publications. Aktouf, O. (1992). Management and theories of organizations in the 1990s: Toward a critical radical humanism? Academy of Management Review, 17(3), 407-431.

Alvesson, M., Bridgeman, T., \& Willmot, H. (2010). Introduction. In M. Alvesson, T. Bridgeman, \& H. Willmot (Eds.), Oxford handbook of critical management studies (pp. 1-23). Oxford, UK: Oxford University Press.

Alvesson, M., \& Willmot, H. (1992). On the idea of emancipation in management and organization studies. Academy of Management Review, 17(3), 432-484.

American Psychiatric Association. (1994). Diagnostic and statistical manual of mental disorders. Washington, DC: American Psychiatric Association.

Avolio, B.J., \& Gardner, W.L. (2005). Authentic leadership development: Getting to the root of positive forms of leadership. Leadership Quarterly, 16(3), 315-338.

Avolio, B.J., Walumbwa, F.O., \& Weber, T.J. (2009). Leadership: Current theories, research, and future directions. Annual Review of Psychology, 60, 421-449.

Basker, E. (2005a). Selling a cheaper mousetrap: Wal-Mart's effect on retail prices. Journal of Urban Economics, 58(2), 203-229. 
Basker, E. (2005b). Job creation or destruction? Labor-market effects of Wal-mart expansion. Review of Economics and Statistics, 87(1), 174-183.

Berg, J.M., Wrzesniewski, A., \& Dutton, J.E. (2010). Perceiving and responding to challenges in job crafting at different ranks: When proactivity requires adaptivity. Journal of Organizational Behavior, 31(2-3), 158-186.

Bernstein, S.D. (2003). Positive organizational scholarship: Meet the movement: An interview with Kim Cameron, Jane Dutton, and Robert Quinn. Journal of Management Inquiry, 12(3), 266-271.

Brass, D.J. (2001). Social capital and organizational leadership. In S.J. Zaccaro, \& R.J. Klimoski (Eds.), The nature of organizational leadership. San Francisco: Jossey-Bass.

Bright, D., Cameron, K.S., \& Caza, A. (2006). The amplifying and buffering effects of virtuousness in downsized organizations. Journal of Business Ethics, 64(3), 249-269.

Cameron, K. (2006). Good or not bad: Standards and ethics in managing change. Academy of Management Learning \& Education, 5(3), 317-323.

Cameron, K.S. (2007). Positive organizational scholarship. In S.R. Clegg, \& J.R. Bailey (Eds.), International encyclopedia of organizational studies. Beverly Hills: Sage Publications.

Cameron, K.S. (2008a). Positively deviant organizational performance and the role of leadership values. Journal of Values Based Leadership, 1, 67-83.

Cameron, K.S. (2008b). Paradox in positive organizational change. Journal of Applied Behavioral Science, 44(1), 7-24.

Cameron, K.S., Bright, D., \& Caza, A. (2004). Exploring the relationships between organizational virtuousness and performance. American Behavioral Scientist, 47(6), 766790 .

Cameron, K.S., \& Caza, A. (2002). Organizational and leadership virtues and the role of forgiveness. Journal of Leadership \& Organizational Studies, 9(1), 33-48.

Cameron, K.S., \& Caza, A. (2004). Contributions to the discipline of positive organizational scholarship. American Behavioral Scientist, 47(6), 731-739.

Cameron, K.S., Dutton, J.E., \& Quinn, R.E. (2003a). Foundations of positive organizational scholarship. In K.S. Cameron, J.E. Dutton, \& R.E. Quinn (Eds.), Positive organizational scholarship: Foundations of a new discipline (pp. 3-13). San Francisco: Berrett-Koehler Publishers Inc.

Cameron, K.S., Dutton, J.E., \& Quinn, R.E. (2003b). Positive organizational scholarship: Foundations of a new discipline. San Francisco, CA: Berrett-Koehler Publishers Inc.

Cameron, K.S., Dutton, J.E., Quinn, R.E., \& Wrzesniewski, A. (2003). Developing a discipline of positive organization scholarship. In K.S. Cameron, J.E. Dutton, \& R.E. Quinn (Eds.), Positive organizational scholarship: Foundations of a new discipline (pp. 361370). San Francisco: Berrett-Koehler Publishers Inc. 
Carmeli, A., \& Spreitzer, G.M. (2009). Trust, connectivity, and thriving: Implications for innovative behaviors at work. Journal of Creative Behavior, 43(3), 161-191.

Caza, A., Barker, B.A., \& Cameron, K.S. (2004). Ethics and ethos: The buffering and amplifying effects of ethical behavior and virtuousness. Journal of Business Ethics, 52(2), 169-178.

Caza, A., \& Cameron, K.S. (2008). Positive organizational scholarship: What does it achieve? In S. Clegg, \& C.L. Cooper (Eds.), SAGE handbook of organizational behaviour (pp. 99116). Thousand Oaks, CA: Sage.

Center for Positive Organizational Scholarship. (n.d.). Positive organizational scholarship: Measuring impact. University of Michigan, Ann Arbor, MI. Retrieved March 18, 2007 from http://www.bus.umich.edu/Positive/PDF/POS-Measuring Impact.pdf

Center for Positive Organizational Scholarship. (2007). The first five years: July 2002-June 2007. University of Michigan, Ann Arbor, MI. Retrieved March 18, 2007 from http://www.bus.umich.edu/Positive/CPOS/About\%20the\%20Center/reports.ht ml.

Center for Positive Organizational Scholarship. (2010). CPOS: 2008-2009 highlights of activities. University of Michigan, Ann Arbor, MI.

Cleland, C.E., \& Chyba, C.F. (2002). Defining 'life.'. Origins of Life and Evolution of the Biosphere, 32, 387-393.

Cogliser, C.C., \& Schriesheim, C.A. (2000). Exploring work unit context and leader-member exchange: A multi-level perspective. Journal of Organizational Behavior, 21, 487-511.

Dirks, K.T., \& Ferrin, D.L. (2002). Trust in leadership: Meta-analytic findings and implications for research and practice. Journal of Applied Psychology, 87(4), 611-628.

Dutton, J.E., \& Glynn, M. (2008). Positive organizational scholarship. In J. Barling \& C.L. Cooper (Eds.), Sage Handbook of Organizational Behavior Vol. 1 (pp. 693-712). London: Sage Publications.

Dutton, J.E., Glynn, M., \& Spreitzer, G.M. (2006). Positive organizational scholarship. In J.H. Greenhaus \& G.A. Callanan (Eds.), Encyclopedia of Career Development (pp. 641-644). Thousand Oaks, CA: Sage Publications.

Dutton, J.E., Roberts, L.M., \& Bednar, J. (2010). Pathways for positive identity construction at work: Four types of positive identity and the building of social resources. Academy of Management Review, 35(2), 265-293.

Dutton, J.E., \& Sonenshein, S. (2009). Positive organizational scholarship. In S.J. Lopez (Ed.), Encyclopedia of positive psychology (pp. 737-742). Malden, MA: Blackwell Publishing.

Dutton, J.E., Worline, M.C., Frost, P.J., \& Lilius, J. (2006). Explaining compassion organizing. Administrative Science Quarterly, 51(1), 59-96.

Fineman, S. (2006). On being positive: Concerns and counterpoints. Academy of Management Review, 31(2), 270-291. 
Fournier, V., \& Grey, C. (2000). At the critical moment: Conditions and prospects for critical management studies. Human Relations, 53(1), 7-32.

George, J.M. (2004). [Review of the book Positive organizational scholarship: Foundations of a new discipline, by K.S. Cameron, J.E. Dutton, \& R.E. Quinn (Eds.)]. Administrative Science Quarterly, 49(2), 325-330.

Gittell, J.H., Cameron, K., Lim, S., \& Rivas, V. (2006). Relationships, layoffs, and organizational resilience: Airline industry responses to September 11. Journal of Applied Behavioral Science, 42(3), 300-329.

Goetz, S.J., \& Rupasingha, A. (2006). Wal-Mart and social capital. American Journal of Agricultural Economics, 88(5), 1304-1310.

Goetz, S.J., \& Shrestha, S.S. (2009). Explaining self-employment success and failure: Wal-Mart versus Starbucks, or Schumpeter versus Putnam. Social Science Quarterly, 91(1), 22-38.

Goetz, S.J., \& Swaminathan, H. (2006). Wal-Mart and county-wide poverty. Social Science Quarterly, 87(2), 211-226.

Grant, A.M., Dutton, J.E., \& Rosso, B.D. (2008). Giving commitment: Employee support programs and the prosocial sensemaking process. Academy of Management Journal, 51(5), 898-918.

Grant, D., Iedema, R., \& Oswick, C. (2010). Discourse and critical management studies. In M. Alvesson, T. Bridgeman, \& H. Willmot (Eds.), Oxford handbook of critical management studies (pp. 213-231). Oxford, UK: Oxford University Press.

Heaphy, E.D., \& Dutton, J.E. (2008). Positive social interactions and the human body at work: Linking organizations and physiology. Academy of Management Review, 33(1), 137-162.

Horkheimer, M. (1976). Traditional and critical theory. In P. Connerton (Ed.), Critical sociology: Selected readings (pp. 206-224). Harmondsworth, UK: Penguin.Find this resource:

Hunt, J.G., \& Dodge, G.E. (2001). Leadership déjà vu all over again. Leadership Quarterly, 11, 435-458.

Irwin, E.G., \& Clark, J. (2006). Wall street vs. Main street: What are the benefits and costs of Wal-Mart to local communities? Choices, 21(2).

James, E.H., \& Wooten, L.P. (2005). Leadership as (Un)usual: How to display competence in times of crisis. Organizational Dynamics, 34(2), 141.

Kanov, J., Maitlis, S., Worline, M.C., Dutton, J.E., Frost, P.J., \& Lilius, J.M. (2004). Compassion in organizational life. American Behavioral Scientist, 47(6), 808-827.

Lawrence, K.A., Lenk, P., \& Quinn, R.E. (2009). Behavioral complexity in leadership: The psychometric properties of a new instrument to measure behavioral repertoire. The Leadership Quarterly, 20(2), 87-102. 
Lilius, J.M., Worline, M.C., Maitlis, S., Kanov, J., Dutton, J.E., \& Frost, P. (2008). The contours and consequences of compassion at work. Journal of Organizational Behavior, 29(2), 193-218.

Luthans, F. (2002). The need for and meaning of positive organizational behavior. Journal of Organizational Behavior, 23(6), 695-706.

McKay, C.P. (2004). What is life-and how do we search for it in other worlds? Public Library of Science Biology, 2(9), e302.

Parker, M. (1995). Critique in the name of what? Postmodernism and critical approaches to organization. Organization Studies, 16(4), 553-564.

Quinn, R.W. (2005). Flow in knowledge work: High performance experience in the design of national security technology. Administrative Science Quarterly, 50(4), 610-641.

Quinn, R.W., \& Dutton, J.E. (2005). Coordination as energy-in-conversation. Academy of Management Review, 30(1), 36-57.

Roberts, L.M. (2006). Shifting the lens on organizational life: The added value of positive scholarship - Response. Academy of Management Review, 31(2), 292-305.

Roberts, L.M., Dutton, J.E., Spreitzer, G.M., Heaphy, E.D., \& Quinn, R.E. (2005). Composing the reflected best-self portrait: Building pathways for becoming extraordinary in work organizations. Academy of Management Review, 30(4), 712-736.

Salancik, G.R., Calder, B.J., Rowland, K.M., Leblebici, H., \& Conway, M. (1975). Leadership as an outcome of social structure and process: A multidimensional analysis. In J.G. Hunt, \& L.L. Larson (Eds.), Leadership frontiers (pp. 81-101). Kent, OH: Kent State University.

Spicer, A., Alvesson, M., \& Karreman, D. (2009). Critical performativity: The unfinished business of critical management studies. Human Relations, 62(4), 537-560.

Spreitzer, G., Stephens, J.P., \& Sweetman, D. (2009). The reflected best self field experiment with adolescent leaders: Exploring the psychological resources associated with feedback source and valence. Journal of Positive Psychology, 4(5), 331-348.

Spreitzer, G., Sutcliffe, K., Dutton, J., Sonenshein, S., \& Grant, A.M. (2005). A socially embedded model of thriving at work. Organization Science, 16(5), 537.

Spreitzer, G.M. (2006). Leading to grow and growing to lead: Leadership development lessons from positive organizational studies. Organizational Dynamics, 35(4), 305.Find this resource:

Spreitzer, G.M. (2007). Giving peace a chance: Organizational leadership, empowerment, and peace. Journal of Organizational Behavior, 28, 1077-1095.

Spreitzer, G.M. (2008). A note on the future of positive organizational scholarship. In D. Barry \& H. Hansen (Eds.), Sage handbook of new approaches in management and organization (pp. 501-503). Thousand Oaks, CA: Sage Publications.

Spreitzer, G.M., \& Sonenshein, S. (2004). Toward the construct definition of positive deviance. American Behavioral Scientist, 47(6), 828-847. 
Thompson, P. (2004). Brands, boundaries and bandwagons: A critical reflection on critical management studies. In S. Fleetwood, \& S. Ackroyd (Eds.), Critical realism in action and organization studies (pp. 54-70). London: Routledge.

Uhl-Bien, M. (2006). Relational leadership theory: Exploring the social processes of leadership and organizing. Leadership Quarterly, 17, 654-676.

Weick, K.E. (2006). Faith, guesses, and action: Better guesses in an unknowable world. Organization Studies, 27, 1723-1736.

Wooten, L.P., \& Crane, P. (2002). Nurses as implementers of organizational culture. Nursing Economics, 21(6), 275-279.

Wooten, L.P., \& Crane, P. (2004). Generating dynamic capabilities through a humanistic work ideology: The case of a certified-nurse midwife practice in a professional bureaucracy. American Behavioral Scientist, 47(6), 848-866.

Wooten, L.P., \& James, E.H. (2008). Linking crisis management and leadership competencies: The role of human resource development. Advances in Developing Human Resources, 10(3), 352-379.

Wooten, L.P., Schultz, C., Ford, B., Anderson, L., Waller, A., \& Ransom, S. (2005). Leadership and prenatal health disparities: It takes a village. African American Research Perspectives, 11(1), 17-30. 